\title{
"Todo poder ao povo preto": diálogos sobre práticas colaborativas entre seres em lugares e tempos afrodiaspóricos
}

\author{
Patrícia Marinho de Carvalho* \\ Alice de Matos Soares**
}

CARVALHO, P. M.; SOARES, A. M. "Todo poder ao povo preto": diálogos sobre práticas colaborativas entre seres em lugares e tempos afrodiaspóricos. R. Museu Arq. Etn. 37: 164-177, 2021.

Resumo: Neste artigo, apresentamos uma reflexão sobre experiências vivenciadas no âmbito de um projeto de mobilidade acadêmica direcionado a estudos da diáspora africana. A proposta apresentada para realização da mobilidade foi estruturada a partir do entendimento sobre a emergência e a complexidade do tema e de seus desdobramentos no passado e no presente da sociedade. Ainda levamos em consideração que, apesar da relevância dessas questões socioculturais, ainda são poucos os cursos de graduação e pós-graduação em arqueologia que trazem para a sala de aula o debate contemporâneo envolvendo temas como raça, racismo e antirracismo, essenciais para a formação de estudantes afrodescendentes ou não. O planejamento e realização das atividades se basearam numa alternativa teórico-metodológica afrocentrada e colaborativa, direcionada ao desenvolvimento de um olhar crítico dos estudantes sobre a materialidade afrodiaspórica, passando pela autorreflexão do estudante sobre seu papel numa sociedade marcada pelo racismo estrutural. Para tanto, privilegiamos a inclusão de atividades além daquelas oferecidas no Museu de Arqueologia e Etnologia (MAE-USP) e na Universidade de São Paulo (USP) e incluímos parcerias com não arqueólogues estudiosos da diáspora africana - experiência que denominamos de "orientação colaborativa". Nos 30 dias de mobilidade, Alice realizou pesquisas nas bibliotecas da USP, visitou a reserva técnica do MAE-USP, assistiu a uma banca de defesa de tese e participou de atividades promovidas pelo educativo do MAE-USP. Fora dos portões da universidade, organizamos e frequentamos uma série de atividades relacionadas a temáticas afrodiaspóricas e afrocentradas: debates, rodas de samba, peças teatrais, desfiles, visitas a terreiros, exposições, entre outras. $\mathrm{O}$ resultado da mobilidade não se restringiu ao entrelaçamento de nossas trajetórias acadêmicas, mas também alcançou nossa experiência afrodiaspórica de vida.

Palavras-chave: Arqueologia da diáspora africana; Pensamento afrocentrado; Afroepistemologia, Movimento negro; Colaboração.

"Doutora em Arqueologia pelo Programa de Pós-Graduação do Museu de Arqueologia e Etnologia da Universidade de São Paulo.<patymarinho@yahoo.com.br>

${ }^{* *}$ Graduanda em Arqueologia na Universidade Federal do Oeste do Pará. <alicematos097@gmail.com>

\section{Introdução}

$\square$ ste artigo é desdobramento da

Cnossa comunicação na VI Semana

Internacional de Arqueologia dos Discentes 
do Museu de Arqueologia e Etnologia da Universidade de São Paulo (MAE-USP) e foi idealizado meses antes, durante a elaboração da proposta que viria a nortear a condução do projeto de mobilidade acadêmica da Alice em São Paulo, que aconteceu no mês de abril de 2019. O objetivo é transmitir essa experiência da mobilidade, apresentando um breve resumo de atividades realizadas, bem como refletir sobre aspectos teórico-metodológicos que nortearam sua formulação a partir do entendimento de que essa experiência deveria partir da colaboração, a fim de proporcionar uma maior interação de Alice com a cena afrodiaspórica em execução.

Tendo em vista o encontro entre Patrícia e Alice (que desencadeou uma série de atividades), os objetivos da mobilidade científica e o impacto individual e a reflexão individual gerada, optamos por dividir a narrativa em duas partes, cada uma escrita por uma das autoras deste artigo. A primeira parte é escrita por Patrícia, que formulou a proposta alternativa, colaborativa e afrocentrada e foi responsável direta pela orientação da estudante durante os 30 dias em São Paulo. A segunda parte é escrita por Alice, que descreve suas experiências, refletindo sobre cada atividade realizada.

\section{Primeira parte - trajetórias e colaboração (Paty Marinho)}

No primeiro semestre de 2018, durante os preparativos para a realização daquela que seria a última etapa de campo referente ao meu projeto de doutoramento em Arqueologia pelo Programa de Pós-Graduação em Arqueologia (PPGArq-MAE/USP), junto à comunidade remanescente de Quilombo do Boqueirão, em Vila Bela, Mato Grosso, eu procurava entre colegas arqueólogues quem poderia compor a equipe da ação colaborativa "Levanta, sacode a poeira: arqueologia do abandono e escavações no sítio arqueológico Porto Boqueirão".

Foi durante esse movimento de composição da equipe que a Laura falou: "você tem que levar a Alice!" (Figura 1).

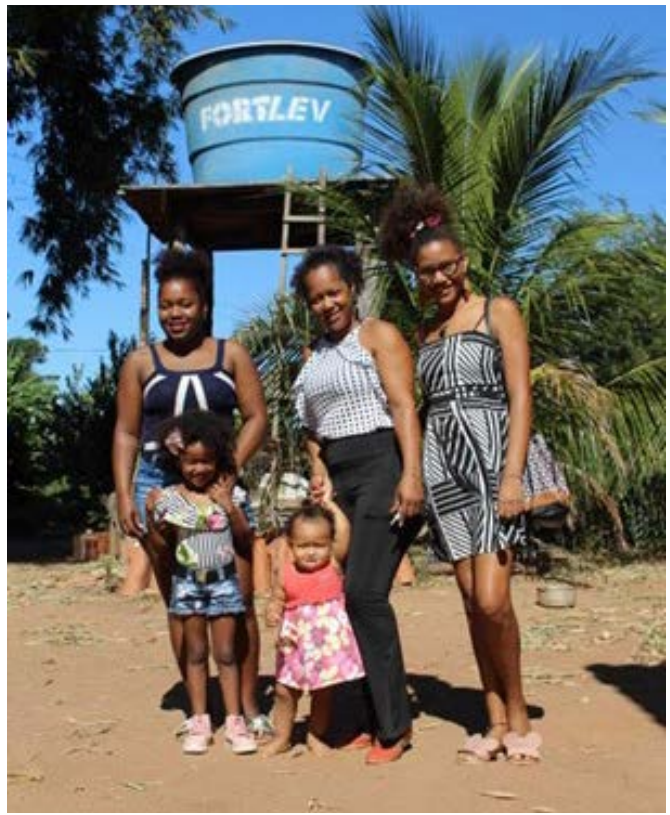

Fig. 1. Da esquerda para a direita: Jéssica, Hadily, Yasmin, Kika e Alice.

Fonte: Acervo da autora.

Foi assim que Alice e eu começamos a compartilhar nossas experiências afrodiaspóricas. Porém, antes de iniciar a reflexão sobre a mobilidade de Alice, considero necessário trazer uma reflexão sobre o início da minha pesquisa junto às comunidades quilombolas de Vila Bela. Esse parêntese tem por objetivo expor, sobretudo, a origem das "ações colaborativas", pois o conceito de colaboração esteve na base da estruturação da mobilidade de Alice em São Paulo.

Quase 10 anos antes de conhecer Alice, precisamente em setembro de 2008, eu chegava pela primeira vez à cidade de Vila Bela da Santíssima Trindade, no Mato Grosso, para dar início à pesquisa de mestrado (Carvalho 2012).

Sempre que sou levada a refletir e a elaborar algo sobre minha experiência em Vila Bela, ou quando lembro com saudades das amizades que fiz por lá, uma cena se repete em minha mente. Naquela manhã de setembro de 2008, quando desci do ônibus, a menos de 30 metros do ponto de ônibus, na esquina da praça da Matriz de Vila Bela, vi que estavam 
“Todo poder ao povo preto”: diálogos sobre práticas colaborativas entre seres em lugares e tempos afrodiaspóricos R. Museu Arq. Etn., 37: 164-177, 2021.

reunidos mais de meia dúzia de pretos-velhos. Esses senhores que ali estavam a prosear observavam o desembarque do ônibus que vinha da capital Cuiabá.

Essa cena ancestralmente familiar me provocou alegria, que foi aumentando a cada passo dado em direção à "Casa Azul”, pois fui observando aquelas senhoras nas janelas e portas de suas casas de outros tempos, as crianças e adultos que começavam a transitar pela rua. Sim, eu havia chegado à "Vila Bela dos Pretos", como definiu Maria de Lourdes Bandeira (1988).

Além da alegria eufórica, senti uma sensação de pertencimento. Não, eu não sou filha de Vila Bela, não sou mato-grossense, tampouco sou quilombola ou fui criada no meio rural. Nasci e cresci na periferia da zona sul de São Paulo, mas minha relação com o povo de Vila Bela é ancestral e todas as negras e negros da cidade de Vila Bela são meu povo, pois somos todos descendentes da diáspora africana e nossos ancestrais batucam no infinito.

Esse sentimento de pertencimento também foi estimulado pelo acolhimento. Em Vila Bela tenho amigas e amigos amados, dos quais recebi apoio, ensinamento e afeto, com os quais compartilhei momentos de aprendizado, de alegria, de tristeza e de festança. Na relação que estabeleci com as pessoas por meio da pesquisa, não fiquei em busca de uma suposta neutralidade científica, como se eu estivesse acima dos demais, mas me coloquei como mais um dos participantes dessa experiência de pesquisa. Também não forjei uma distinção entre a Paty mulher negra, mãe de filho, periférica, feminista, extrovertida e a acadêmica que chegara ali para desenvolver sua pesquisa arqueológica. $\mathrm{O}$ diálogo sempre foi muito franco, fluido e direto, marcado pela conciliação, e não pela imposição.

Durante a experiência junto à comunidade, constantemente me questionava e ainda me questiono sobre a relação que estabeleci com as pessoas, com o lugar e seus seres etéreos, em termos de reciprocidade, de devolutiva dos resultados da pesquisa. Após 11 anos, todo conhecimento que acumulei junto à comunidade está materializado em títulos, dissertação, tese, artigos, e permanece o questionamento: e a contrapartida, o que ficou para a comunidade? Um calhamaço recheado de conteúdo arqueológico sobre território e ancestralidade? Talvez esse seja um questionamento eterno.

Tudo bem quanto a isso, pois tomei consciência de que esse questionamento impulsiona minha caminhada no sentido de que o fazer arqueológico seja uma prática cada vez mais representativa dos anseios das pessoas e comunidades envolvidas, com as quais trabalho. Para tanto, tenho trazido a reflexão sobre "colaboração" e experimentado formas de estabelecer relações simétricas entre todos os envolvidos nos projetos e experiências profissionais e/ou acadêmicas das quais participo.

O termo "ação colaborativa" foi elaborado durante meu doutoramento (Carvalho 2018) e abarcou os pressupostos da colaboração em arqueologia (ColwellChanthaphonh 2009) enquanto método para propiciar a participação e o engajamento dos envolvidos nas comunidades.

A primeira ação colaborativa surgiu, coincidentemente, durante a realização da IV Semana de Arqueologia, em 2015, quando fui convidada pelos colegas para ser a anfitriã do evento de encerramento. Assim, surgiu mais uma edição do "Acarajé da Paty", só que da informalidade das festas do meu aniversário, resolvi aceitar o desafio de fazer acarajés num evento oficial dos estudantes de arqueologia do MAE-USP. Essa foi a primeira ação colaborativa do doutorado, pois parte dos recursos arrecadados foram destinados à realização da primeira etapa de campo no Quilombo do Boqueirão.

A experiência foi bem-sucedida e inspirou novas ações colaborativas. A ação "Acarajé e Arqueologia" passou a ter como objetivo principal não a arrecadação de fundos para a pesquisa, mas sim provocar o debate entre arqueólogues sobre temas relacionados não só à materialidade afrodiaspórica, mas que a conectassem à discussão de temas como o racismo estrutural - um sistema discriminatório fundamentado na raça cujas práticas levam à criação e/ou manutenção de privilégios ou desvantagens (Almeida 2018). 
Esse movimento foi impulsionado pelo entendimento de que a arqueologia brasileira tem um desafio, sobretudo quando o tema envolve contextos ou seres afrodiaspóricos. Há um desconhecimento generalizado sobre a cultura e história das populações afro-brasileiras que as Leis $n .^{\circ} 10.639$, de 9 de janeiro de 2003, e n. ${ }^{\circ} 11.645$, de 10 de março de 2008 tentam corrigir. Porém, há uma defasagem generalizada na sociedade e os(as) estudantes de arqueologia não escapam disso. Os cursos de graduação (também de pós-graduação) estão aquém de suprir essa defasagem, pois para tal deveriam minimamente ter a "arqueologia da diáspora africana" como disciplina obrigatória em seus currículos. É preciso incorporar visões e experiências diaspóricas por meio de questões teórico-metodológicas, mas também pelo compromisso ético que penso que a arqueologia deve ter com os coletivos humanos estudados, além de garantir a representativa negra de alunos afrodescendentes, colaborando com a eliminação de racismos e fascismos que levam à invisibilidade.

Nesse sentido, as ações colaborativas passaram a designar também cada uma das etapas de campo que realizamos em Vila Bela da Santíssima Trindade:

(1) Oficina da Memória: estudos sobre a formação do registro arqueológico.

(2) Pisa nesse chão com força: prospecção e mapeamento do Sítio Arqueológico Porto Boqueirão (SArqPB) e Oficina de Arqueologia Experimental - casa tradicional.

(3) Levanta, sacode a poeira: arqueologia do abandono e escavações no sítio arqueológico (etapa que contou com a participação de Alice).

Cada uma dessas campanhas que foram organizadas para realizar etapas previstas no plano de pesquisa contou com a participação, além dos quilombolas do Boqueirão, de estudantes - arqueólogues e não arqueólogues - com interesse nos estudos sobre diáspora africana ou sobre sua própria ancestralidade.

As ações colaborativas também foram pensadas para transmitir de forma acessível as diversas etapas do trabalho arqueológico a ser desenvolvido, garantindo a participação consciente da comunidade nas ações de campo. A metodologia foi sendo construída etapa por etapa, com o objetivo de ser didática e inclusiva, com múltiplas linguagens, como textos, ilustrações, vídeos, áudios e a palavra.

Já no trabalho final, a tese teve como principal critério em sua elaboração se converter em um registro que pudesse ser apropriado pelos moradores de Vila Bela, sobretudo pelos membros da família Frazão de Almeida, com quem trabalhei mais intensamente.

A tese Visibilidade do Negro: arqueologia do abandono na comunidade quilombola do Boqueirão - Vila Bela/MT (Carvalho 2018) é também um memorial da conformação do território quilombola, das transformações na paisagem, da materialidade e da vida de moradores da comunidade quilombola do Boqueirão. Para tanto, recorri ao registro fotográfico, não somente como material de divulgação no meio acadêmico e como registro documental do trabalho de campo (Silva, Mützenberg \& Cisneiros 2012), mas prioritariamente para tornar seu conteúdo acessível à maioria dos membros da comunidade, por meio da leitura das imagens.

A participação de Alice na última etapa (Levanta, sacode a poeira) foi fundamental para alguns direcionamentos da minha própria aventura acadêmica com o fim do doutorado e o eterno questionamento sobre a contrapartida e formas de devolutiva à comunidade.

Independentemente da possibilidade de desenvolver novos projetos com os quilombolas do Boqueirão que levem benefícios diretos para as condições de vida da comunidade, passei a entender que a devolutiva que eu busco pode ser revertida não diretamente à comunidade. A visibilidade social do Negro, uma das questões centrais da investigação de doutorado, extrapola os limites da comunidade quilombola do Boqueirão para alcançar outros afrodescendentes na diáspora africana.

Quando pensamos no título da nossa comunicação para a VI Semana de Arqueologia - "Todo poder ao povo preto" -, fizemos essa referência pensando nos dez pontos dos Panteras Negras, destacando um aspecto que considero central nesse processo 
“Todo poder ao povo preto”: diálogos sobre práticas colaborativas entre seres em lugares e tempos afrodiaspóricos R. Museu Arq. Etn., 37: 164-177, 2021.

que envolve a visibilidade social: um sistema de ensino que funcione para o povo preto. Guardadas as distâncias temporais e espaciais, nós, estudantes afrodescendentes brasileiros, estamos inseridos numa engrenagem estrutural na qual os acessos são dificultados por conta de uma discriminação invisibilizada.

Nesse sentido, uma devolutiva possível seria em prol do povo negro numa perspectiva mais abrangente. A docência se mostrou como um caminho possivel e foi nesse sentido que pensei em como construir uma "orientação colaborativa" e afrocentrada para receber Alice em São Paulo durante os 30 dias de mobilidade.

Tanto Alice, em sua graduação na Universidade Federal do Oeste do Pará (Ufopa), quanto eu em minha pós-graduação nunca tivemos uma disciplina de arqueologia da diáspora africana ou de proposta similar, muito menos tivemos diálogos em quaisquer outras disciplinas que nos ajudassem a pensar simplesmente no nosso corpo negro no espaço acadêmico. Nossas trajetórias se cruzaram quando constatamos que nosso conhecimento sobre diáspora, além da nossa própria ancestralidade, começou a ser construído fora da sala de aula, participando e organizando movimentos negros.

As experiências vivenciadas por Alice e eu durante a Mobilidade foram orientadas num sentido alternativo e independente (Silva 2012). Nós transitamos não apenas dentro da Universidade de São Paulo (USP), mas principalmente fora dela, guiadas por uma proposta afropedagógica de orientação inspirada na "pedagoginga" (Rosa 2013).

Em 2010, fui convidada para participar de um projeto de educação popular, desenvolvido por Allan da Rosa, que formulou o conceito de pedagoginga. $\mathrm{O}$ projeto tinha como objetivo o ensino de história e cultura de matriz africana, mantendo o protagonismo periférico da discussão e aportando conhecimentos que estavam sendo produzidos na universidade. Como define Allan, pedagoginga é:

\section{[um] movimento trançado à dinâmica} que os movimentos literários, arteiros e sociais das quebradas paulistanas mantêm acesa, mas que parece pedir menos espetáculo e mais trabalho de horta, precisar mais de debate do que do desejo vislumbrado de se enroscar nas rédeas de quem nos pisoteia, ou seja, questionar o que seja se adentrar ao sistema e que volta e meia comemora ultrapassar a 'linha da exclusão', se é que isso realmente seja possivel [...] Pedagoginga é firmar no fortalecimento de um movimento social educativo que conjugue o que é simbólico e o que é pra encher barriga (Rosa 2013: 15).

Nesse projeto, nós realizamos a oficina "Quilombos: histórias e sentidos, imaginário e arqueologia", fruto da reflexão que eu estava fazendo sobre arqueologia e quilombo durante o mestrado. Nesse momento eu transitava entre terreiros e quilombos - territórios negros de resistência ao sistema colonial opressor -, seguindo o caminho das folhas e entendendo que determinadas árvores tinham um papel fundamental na produção e manutenção de um sistema de crenças, sendo capazes de evocar nas pessoas todo tipo de memória, inclusive a de seus antepassados. percebi então que o conteúdo simbólico desse conhecimento ancestral tem reflexos na maneira como os grupos quilombolas percebem e constroem a paisagem (Carvalho 2012).

Nesse sentido, entendo que as afropedagogias, como a pedagoginga, são alimentadas por resistência e memória, estão diretamente relacionadas à ancestralidade. Inicialmente são praticadas no âmbito familiar e se expandem para os coletivos e espaços de socialização e ação política, pensados enquanto movimento negro. Esses espaços podem ser os diversos grupos de debate e ação política, de combate ao racismo, espaços de resistência cultural como os grupos de capoeira, ou de manifestações culturais de matriz africana, comunidades afrorreligiosas e de movimento negro propriamente dito, como o Coletivo de Estudantes Negros da Ufopa Alessandra Caripuna, do qual Alice é integrante.

Quando penso em movimento negro, penso em espaços e movimentos que me transpassaram ao longo da vida e nem sempre eram espaços burocraticamente constituídos. 
Essa noção de movimento negro é trazida por Nilma Lino Gomes, que chamou a atenção para o potencial educador do movimento negro.

[...] no Brasil, as estratégias de conhecimentos sobre as relações raciais e as questões da diáspora africana, que hoje fazem parte das preocupações teóricas das diversas disciplinas das ciências humanas e sociais, só passaram a receber o devido valor epistemológico e político devido à forte atuação do Movimento Negro. [...] esse mesmo movimento social que fez e faz a tradução intercultural das teorias e interpretações críticas realizadas sobre a temática racial no campo acadêmico, para a população negra e pobre fora da universidade (Gomes 2017: 17).

Foi nesse sentido de "tradução intercultural”, mas também de troca de saberes, entendendo o exercício da multivocalidade como a alternativa de construção do conhecimento, que partimos para nossa experiência de mobilidade.

Antes e durante os 30 dias de mobilidade, entrei em contato com amigos e amigas de longa data, cuja pesquisa, vivência, trabalho, crença ou militância têm relação com a diáspora africana. Cotidianamente nós éramos informadas sobre atividades na pauliceia.

E realmente participamos de atividades marcantes que com certeza ampliaram nossos horizontes sobre a diáspora africana por meio da construção de uma educação libertária, transgressora (hooks 2013) e afrocentrada.

\section{Segunda parte: do norte ao sul, experiência afrodiaspórica}

Meu nome é Alice, nasci e fui criada em Santarém, no Pará. Sou graduanda em Arqueologia pela Universidade Federal do Oeste do Pará (Ufopa) e quero registrar que a minha trajetória acadêmica foi/está sendo um tanto difícil. Fui vítima de crime de racismo na universidade, o que me levou a procurar grupos e pessoas que pudessem me ajudar a superar essa experiência.
Hoje faço parte do Coletivo Negro Alessandra Caripuna, que fundei junto com outros colegas estudantes da Ufopa em 11 de julho de 2017. O coletivo foi criado justamente para suprir a falta de representação na universidade, para fortalecer os estudantes negros e combater o racismo dentro e fora da instituição. Está diretamente ligado a um esforço em discutir e garantir que as politicas públicas da universidade englobem os afrodescendentes. Também faço parte do Movimento Tapajós Vivo (MTV), que atua na luta contra todos os empreendimentos que ameaçam a vida às margens do rio Tapajós.

Em 2018 fui convidada pela Paty Marinho para participar de uma etapa de campo de sua pesquisa de doutorado em Vila Bela da Santíssima Trindade. Em maio daquele ano se deu nosso primeiro encontro.

Durante 20 dias, estive com ela na comunidade remanescente do quilombo Boqueirão e essa foi minha primeira experiência e contato com a temática da diáspora africana fora da minha cidade. Na época, só havia feito uma escavação (em contexto de ocupações pré-coloniais), então participar da escavação no Boqueirão contribuiu acadêmica e pessoalmente, pois obtive experiência e formação, dado que era um contexto totalmente diferente do que já tinha visto, além de ter esse contato bem próximo com os moradores da comunidade, que me receberam muito bem.

Essa experiência colaborativa em Vila Bela foi fundamental para a definição do que quero fazer, que é discutir e contribuir com as comunidades negras da minha região, a partir de uma perspectiva afrodiaspórica e afrocentrada.

Em 2018, Paty e eu tivemos mais um encontro, pois a convidamos para participar dos debates e dar um minicurso durante a Semana de Arqueologia e Antropologia com o tema "Dos Palmares aos Santos: Vivenciando Dandaras", que abordaria africanidades e diáspora africana, gênero (sexualidade, transgeneridade), perpassando preconceito e racismo. Esse evento foi uma das formas que o programa encontrou para tentar preencher a lacuna de formação dos discentes a partir da demanda por discussões sobre gênero e negritude. 
“Todo poder ao povo preto”: diálogos sobre práticas colaborativas entre seres em lugares e tempos afrodiaspóricos R. Museu Arq. Etn., 37: 164-177, 2021.

Porém, a inexistência de uma disciplina que discutisse a temática da diáspora africana me levou a procurar a professora Anne Rapp Py-Daniel para pleitear uma bolsa de mobilidade acadêmica, em São Paulo, orientada pela Paty Marinho, com quem já havia estabelecido uma relação de amizade por meio de vivências enquanto mulheres diaspóricas e por ela ser uma referência nos estudos arqueológicos da diáspora africana.

Dessa forma, por intermédio do Programa de Mobilidade Acadêmica Externa Temporária Nacional - edital promovido pela PróReitoria de Ensino de Graduação da Ufopa -, fui recebida oficialmente pela professora Fabíola Silva no MAE-USP e fui orientada nos meus estudos da diáspora pela Paty Marinho, então orientanda de doutorado do museu.

As atividades foram tanto universitárias (defesa de tese, conversas com pesquisadores, consulta a acervos de bibliotecas, visita em reserva técnica, pesquisa de campo) quanto fora do ambiente da universidade (eventos religiosos, rodas de conversas, oficinas, exposições, lançamentos de livros, manifestações culturais).

Durante a mobilidade, realizei levantamentos bibliográficos, reunindo textos das diversas áreas que discutem a diáspora africana. Além das bibliotecas da USP, também acessei o acervo pessoal de Paty. Ampliei a pesquisa bibliográfica a partir das indicações que foram dadas nas rodas de conversas que participei e por meio de plataformas de divulgação de trabalhos referentes à cultura africana, tais como o Acervo África (Figura 2), cuja biblioteca reúne uma coleção de mais de 500 obras composta por livros, periódicos, dissertações e teses. O acervo também conta com um catálogo de 200 filmes, em sua maioria de cineastas africanos, disponíveis para consulta local, além de um banco de imagens com fotografias disponíveis para consulta on-line.

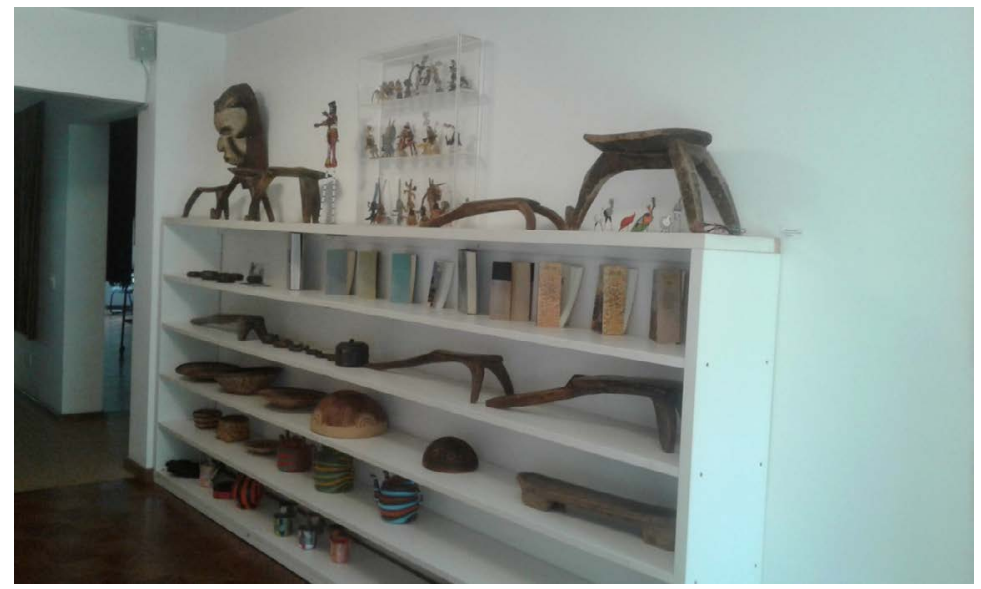

Fig. 2. Acervo África.

Fonte: Acervo da autora.

Durante nossa visita ao Acervo África, Luciana Ramos (Luli) me deu um exemplar da revista $\mathrm{O}$ Menelick $2^{\circ}$ Ato, um projeto editorial de reflexão e valorização da produção cultural e artística da diáspora negra com destaque para o Brasil, que também está disponível on-line ${ }^{2}$. Com o auxílio dessa revista, tomei

2 Revista O Menelick 2॰ Ato, disponivel em: <https://bit.ly/ $3 \mathrm{Ha} 1 \mathrm{i} 5 \mathrm{u}>$. conhecimento de várias autoras e autores que estão discutindo a temática afrodiaspórica. Também tive acesso à revista eletrônica Òkòtó, que é um espaço de divulgação de textos e reflexões do Kilûmbu Òkòtó, uma escola de educação em dinâmica racial que visa a emancipação do povo preto em todas as esferas ${ }^{3}$.

3 Revista Ôkótó, disponivel em: <https://bit.ly/ 3n2GQv9>. 
Para além da pesquisa bibliográfica, conheci diversos espaços na cidade de São Paulo que detêm materiais relacionados à diáspora africana, tais como o Centro de Arqueologia de São Paulo (Casp), que faz parte do Departamento de Patrimônio Histórico (DPH), da Secretaria Municipal de Cultura. O Casp é uma instituição de guarda e pesquisa com acervo composto pelos materiais escavados nas várias regiões da cidade de São Paulo. No Casp, fomos recebidas pela arqueóloga Paula Nishida. Segundo a arqueóloga, uma das coleções mais antigas foi formada por meio das pesquisas desenvolvidas pelo DPH.

O local escolhido para a implantação do Casp é o Sítio Morrinhos, imóvel de valor histórico que faz parte do acervo das casas históricas da prefeitura do município de São Paulo. O acervo é, em sua maioria, dos séculos XIX e XX. Desde 1979, quando foi firmado acordo entre o DPH e o Museu Paulista da USP, desenvolve-se o Programa de Arqueologia Histórica da cidade de São Paulo.

Também visitamos o Museu Afro Brasil, detentor de um grande acervo, que tem como objetivo preservar e contribuir com a divulgação da herança artística e cultural do negro no Brasil. Pude observar que o acervo do museu conta outra história do Brasil, não de forma estática, mas uma história que é viva e que procura desconstruir o imaginário sobre a população negra, que foi articulado pela ótica da inferioridade. $\mathrm{O}$ museu apresenta um acervo riquíssimo que traz um pouco da diversidade e beleza da cultura dos povos originários do continente africano que foram reduzidos à escravidão no Brasil.

Outro espaço importante que visitei foi o Acervo África que, além de ser um espaço de exposição, é um espaço de pesquisa. A coleção é fruto das viagens de pesquisa da historiadora Daniela Moreau, coordenadora e mantenedora do acervo, que conta com peças oriundas de contextos africanos plurais em suas culturas e organizações sociais, colaborando com o entendimento do público sobre a cultura material africana. Assim, as atividades desenvolvidas no espaço têm por objetivo proporcionar à população brasileira elementos para conhecer a diversidade sociocultural africana, contribuindo para a difusão das matrizes africanas que geraram a cultura brasileira, entre outras. ${ }^{4}$

Fazendo uso do Acervo África, tive contato com a gestora de projetos Luciane RamosSilva, artista da dança e doutora em Artes da Cena pela Universidade Estadual de Campinas (Unicamp) e do conselho editorial da revista O Menelick $2^{\circ}$ Ato. Luciane ainda me contou um pouco da sua trajetória acadêmica enquanto mulher negra, que eu julgo ser muito importante, pois são poucos os pesquisadores negros, e é bom saber que estamos ocupando diversos espaços, mesmo que lentamente.

O MAE-USP também tem uma coleção com materiais africanos, oriundos principalmente do leste da África e do Mediterrâneo. Percebi que a coleção é bem variada, apresentando roupas, máscaras, esculturas, cetros, tanto em metal quanto em madeira, ferramentas de fabricação das máscaras, diversos adornos em metais, entre outros itens e materiais.

A convite de Liliane Braga, educadora e pesquisadora do Centro de Estudos Culturais Africanos e da Diáspora da Pontifícia Universidade Católica de São Paulo (PUC/SP), visitamos a exposição de arte Tshimbondation (integração), do artista plástico e expositor congolês Shambuyi Wetu. $\mathrm{O}$ artista trabalha com esculturas e pinturas, abordando diversos temas sobre as narrativas e experiências da diáspora e a situação do negro no mundo. A exposição continha 19 telas feitas com a técnica de colagem, utilizando jornais e revistas, formando rostos e silhuetas de pessoas. Wetu desenvolveu sua carreira no Brasil desde 2014 e essa foi sua primeira exposição individual, que pretendeu inspirar a questão do pertencimento com base em sua experiência como imigrante e em seu próprio processo de integração artística no contexto brasileiro. As colagens com materiais recicláveis são um convite à ressignificação da condição marginal, segundo o artista.

4 Informações sobre o Acervo África disponíveis em: <https://bit.ly/3C7QpNA>. Acesso em: data. 
“Todo poder ao povo preto”: diálogos sobre práticas colaborativas entre seres em lugares e tempos afrodiaspóricos R. Museu Arq. Etn., 37: 164-177, 2021.

Em mais um encontro com Liliane Braga, participamos do seminário "Articulando saberes: educação e arte da diáspora na América Latina”, organizado pelo Sesc 24 de maio, em que nós participamos da palestra "Desde dentro: um panorama da diáspora negra na América Latina”, por Sheila Walker, dos Estados Unidos. A conferência contou com o lançamento do livro Conhecimento desde dentro: os afro-sul-americanos falam de seus povos e suas histórias (2019), organizado pela palestrante. A discussão sobre esse panorama da diáspora negra se deu a partir de um documentário produzido pela autora em diversas localidades da América Latina, como Brasil, Uruguai e Panamá, incluindo também pesquisas realizadas no continente africano, Índia, Turquia e em outros países com histórias coloniais. O documentário apresentado durante a palestra abordou múltiplos rostos familiares (negros) em lugares inesperados. Na sua pesquisa antropológica, a autora constatou que há uma base semelhante nas culturas africanas (mas nem todas) e se questiona de onde vem a negação à cultura afro nos Estados Unidos.

Fomos convidadas pelo professor Julio Moracen para assistir a uma de suas aulas na Universidade Federal do Estado de São Paulo (Unifesp), no campus de Guarulhos. A disciplina ministrada pelo professor tratava da História do Teatro Negro e Indígena na América Latina e Caribe. Nessa aula, nós discutimos um pouco o conceito de diáspora no teatro a partir de textos lidos previamente, incluindo temas da antropologia teatral, o estilo do teatro negro, o processo de construção da identidade brasileira, a herança cultural negra e os processos de resistência cultural negra, tais como os quilombos, transculturação, entre outros.

No espetáculo Medea Mina Jeje, encenado por Kenan Bernardes, presenciamos uma performance negra que trata de uma súplica materna, com uma série de cantos e vozes, e percebemos que o grito de Medea é pela liberdade, que aparece como mar revolto, aquele que lhe trouxe a força da África e que a levará de volta. Ao final da apresentação, seguiu-se uma roda de conversa mediada por Liliane Braga, em que discutimos aspectos da diáspora africana com o objetivo de desnaturalizar as ideias que inferiorizam o saber africano e afro-brasileiro.

Durante a inauguração do sarauzódromo espaço para literatura na biblioteca Mário de Andrade, na capital paulista -, tive a oportunidade de conhecer Conceição Evaristo, romancista, contista e poeta, escritora negra que tem bastante influência na literatura brasileira. Suas obras abordam temas como a discriminação racial, de gênero e de classe. Ainda tive a oportunidade de ver Roberta Estrela D'Alva, atriz-MC, diretora, pesquisadora e slammer, que expôs poemas, muitos deles com a temática da diáspora africana, como o poema (de sua autoria) intitulado Diáspora, recitado por ela. As duas escritoras fizeram um tributo a Ruth Guimarães, com leituras de trechos de obras como o romance Águas fundas e cartas que a autora escreveu a Mário de Andrade.

Na roda de conversa "Genocídio da população negra: impactos na saúde mental de jovens negros", organizada pelo coletivo As pretas, pude discutir e pensar a pauta de um novo modelo de resistência, construído na união do povo preto. Discutimos que o racismo não é um problema nosso, uma vez que estruturalmente é dos brancos, mas que infelizmente nos afeta. Assim, percebi que os impactos à saúde mental são grandes, principalmente a solidão, pois quando pessoas negras têm acesso a espaços de poder, permanecem quase que inevitavelmente sendo a única pessoa negra nesses espaços. Também fizemos uma reflexão sobre a saúde mental das crianças e entendemos que é necessário cobrar das escolas posicionamentos, pois os meninos negros são vistos como marginais, a maioria deles inseridos em famílias desestruturadas. Além disso, refletimos sobre a saúde mental coletiva e o cuidado com os nossos.

Essa experiência me levou a refletir sobre como muitas universidades estão alheias aos cuidados com seus alunos, mantendo sistemas de opressão que têm agravado a saúde mental dos estudantes, tal como a minha experiência pessoal infeliz de vivenciar o racismo dentro da instituição.

Ao assistir a defesa da tese de doutorado em arqueologia de Daniella Magri Amaral, 
no MAE-USP, pude conhecer mais e pensar na arqueologia que potencializa as vozes. A tese Loiceiras, potes e sertões: um estudo etnoarqueológico de comunidades ceramistas no agreste central Pernambucano discute como os sertanejos são representados e sua materialidade é pouco visibilizada, pois ainda temos uma arqueologia colonialista, com fetiche na antiguidade. A autora apresenta um pouco do que seria essa materialidade, suas resistências e permanências, como os potes e as jarras do cotidiano doméstico. Fala das loiceiras e seus conhecimentos e de como os potes são veículos de sociabilidade, remetendo tanto à abundância como à escassez. Aborda ainda a noção de patrimônio que, para eles, que difere muito da noção promovida pelo Estado.

No MAE-USP também fui recebida pelo doutorando Fábio Guaraldo Almeida, que me apresentou o seu trabalho em desenvolvimento com comunidades remanescentes de quilombo, falando sobre formas de como atuar junto a populações tradicionais.
No Centro Cultural São Paulo (CCSP), participamos do evento de relançamento da Coleção Feminismos Plurais e lançamento do livro Racismo recreativo (2019), de Adilson Moreira (Figura 3). Conheci de perto autores negros que muito tenho lido e que estão tratando dos mais diversos temas que perpassam o ser negro. Estavam presentes Djamila Ribeiro, Joice Berth, Juliana Borges, Carla Akotirene e Adilson Moreira, que estava lançando seu livro, que segundo ele foi motivado a partir de um caso de racismo. $\mathrm{O}$ autor buscou entender a lógica jurídica e social do humor nas piadas, observando que o humor pode ser usado para demonstrar desprezo pelas minorias sociais. $\mathrm{O}$ livro tem diálogo direto com os outros da coleção Feminismos Plurais, que tratam de lugar de fala, criação de conhecimento, empoderamento, entre outros. Essa foi uma experiência maravilhosa, que me fez também refletir sobre esses muitos debates que a arqueologia aos poucos vem incorporando, com o ingresso de estudante negros por meio do acesso afirmativo.

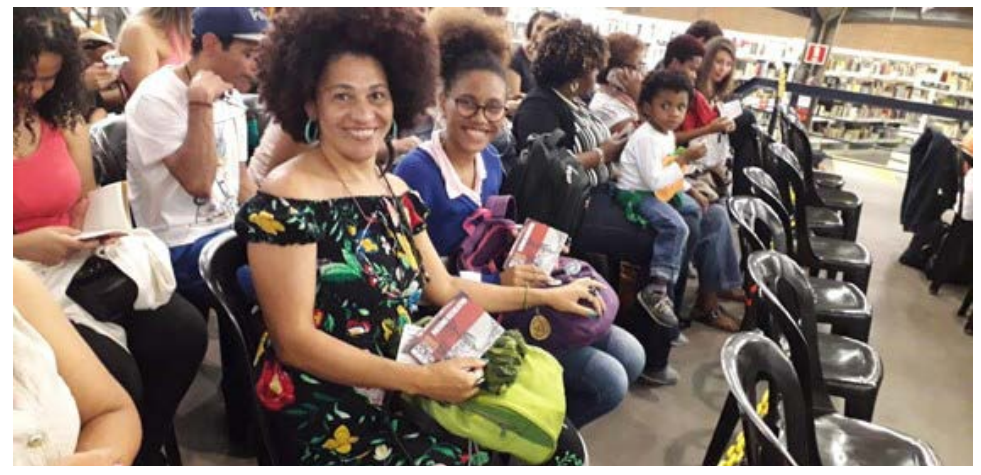

Fig. 3. Paty e eu no lançamento do livro de Adilson Moreira.

Fonte: Acervo da autora.

Outra experiência importante foi o "Afrobrasilidades: da religião à estética Afro-Brasileira" e seus contextos, com as participações da antropóloga e cabeleireira Bruna Mantese, da escritora Paloma Amorim, da arqueóloga Paty Marinho e da artista e maquiadora Sara Silva - estudiosa das religiões de matriz africana que aplica essa temática a seus poemas, desenhos e esculturas. Sara abriu a discussão trazendo informações sobre a profissão de maquiadora, que tem sido desvalorizada pelo número crescente de blogueiras com tutoriais. Segundo Sara, maquiadoras(es) profissionais estudam as personalidades das pessoas para definir qual maquiagem é a mais adequada. Também conversamos sobre a estética e a autoestima da mulher negra. Na sequência, Sara introduziu a discussão sobre a decisão do Supremo Tribunal Federal (STF) sobre a não proibição de sacrifício de animais nas religiões de matriz afro. Bruna Mantese, 
“Todo poder ao povo preto”: diálogos sobre práticas colaborativas entre seres em lugares e tempos afrodiaspóricos R. Museu Arq. Etn., 37: 164-177, 2021.

que é vegana, apresentou vários pontos de vista sobre o tema. Achei importante essa discussão e entendi que existe um grande desconhecimento por parte da população sobre as religiões de matriz africana, o que acaba gerando uma série de preconceitos.

Tive a oportunidade de participar do Sarau Especial do Grupo Cativeiro Capoeira (Figura 4), que hoje tem sede em muitos países e vários lugares do Brasil. Paty Marinho já fez parte do grupo na adolescência, e seu colega, o arqueólogo Fabio Guaraldo Almeida, coincidentemente faz parte do grupo e estava presente. A roda contou com a presença do mestre Alcides, que se formou na primeira turma do Grupo Cativeiro e relatou suas experiências no projeto e relações raciais. Ele fez uma linha do tempo contando um pouco sobre a história dos 40 anos do grupo e os processos da capoeira no Brasil. O grupo tem uma preocupação integral com a formação dos praticantes de capoeira, tanto em relação aos aspectos físicos, técnicos e morais quanto políticos, considerando a capoeira como símbolo de resistência. Essa foi uma experiência pessoal muito boa, em que relembrei os tempos em que era criança, quando jogava capoeira no âmbito de um projeto de assistência. Eu penso que projetos que valorizam a identidade negra são fundamentais para desconstruir muitas ideologias negativas construídas sobre a nossa cultura.

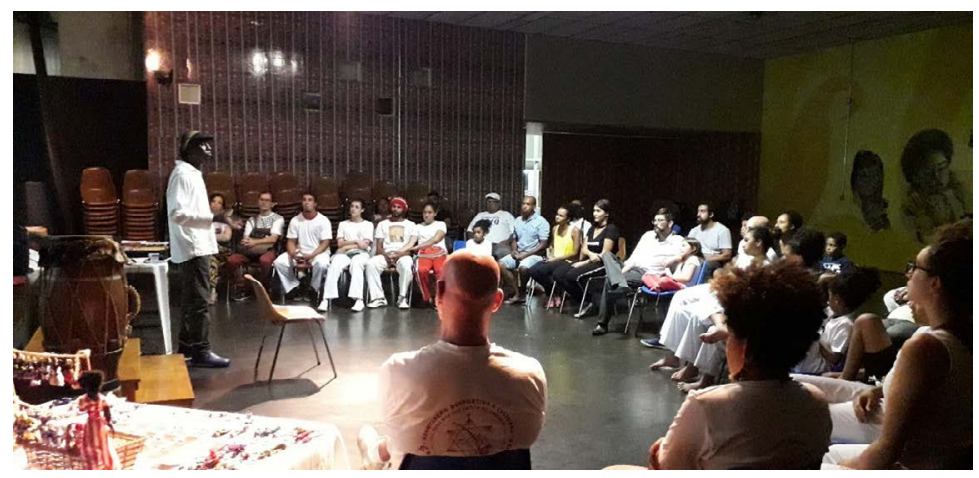

Fig. 4. Sarau do Grupo Cativeiro Capoeira.

Fonte: Acervo da autora.

Outra atividade envolvendo religiões afrobrasileiras foi a visita que fizemos ao terreiro de Umbanda Mãe D’Água Pai das Matas da Mãe Amália - mãe de santo de Paty Marinho. Essa atividade me fez pensar muito em como as coisas mudam nos diferentes lugares, ou seja, têm suas particularidades e regionalismos. Anteriormente havia participado de algumas sessões em um terreiro de umbanda em Santarém e, ao compará-las, observei que as músicas e as entidades são diferentes.

Alguns dias depois do relançamento da coleção Feminismos Plurais, voltamos ao CCSP para assistir um evento em homenagem ao orixá Ogum. Foi um lindo evento, com muita dança e música.

No centro de São Paulo, nas imediações do vale do Anhangabaú, participamos da roda de conversa "Orixás e pretogogias: a espiritualidade é a chave". Foi uma atividade muito interessante, pois pude conhecer um pouco sobre as histórias de alguns orixás. Essa atividade foi organizada pela escola educacional racial Kilûmbu Òkòtó, que propõe uma educação antirracista com foco na consciência espiritual, com vistas a desenvolver nossa mentalidade e nossa inteligência emocional para lidar com o enfrentamento ao racismo. Discutimos principalmente sobre a espiritualidade na educação de crianças negras. Foi uma roda que me mostrou muito sobre como a espiritualidade promove uma conexão e a relação entre coisas, pessoas e lugares.

No "Encontro de organização e ação política: ódio político no poder, na escola e no portão de casa. que fazer?", organizado pela plataforma 
Somos Maioria, vi as múltiplas perspectivas do cenário atual brasileiro. $\mathrm{O}$ encontro foi mediado por Douglas Belchior e a análise de conjuntura foi feita por Weber Lopes, mestre e doutor em Ciências Sociais, e por Flávia Oliveira, jornalista especializada em economia e indicadores sociais, da União de Núcleos de Educação Popular para Negras/os e Classe Trabalhadora (Uneafro Brasil). Weber apresentou um panorama dos governantes do Brasil até os dias atuais, e vimos que o contexto em que estamos inseridos não é tão novo assim.

Nessa discussão, Flávia afirmou que quem pode falar melhor sobre o Brasil somos nós, a massa popular. Para Flávia, a universidade precisa aprender sobre nós, nossos saberes, conhecimento ancestral, comunidades de terreiros. Nesse sentido, trago uma fala que muito me cativou e despertou o melhor que somos: "quanto mais eu estudo, mais preta eu fico". Temos que enxergar essa potência, pois o conhecimento negro sempre foi invisibilizado. Em sua análise da conjuntura, a pesquisadora apontou que mais de 15 milhões de pessoas estão abaixo da linha de pobreza (miséria) e sobrevivem com dois dólares por dia.

Outro ponto de sua fala que me chamou a atenção foi que população negra tem uma ligação muito forte com o empreendedorismo, principalmente as mulheres, porém isso não é conhecido, pelo contrário, é invisibilizado, visto como apenas "um corre", uma maneira de sobreviver, não como uma potencialidade ou algo a ser estimulado. A palestrante ainda levantou a discussão sobre o grande impacto da reforma da previdência na vida das mulheres e das populações negra e nordestina, pessoas que mais demoram a se aposentar. Pude perceber como esse modelo de previdência é genocida e que nós precisamos de uma reforma para evitar a continuidade dos custos altos da sociedade que privilegia determinados grupos. Diante disso, a massa popular tem a missão de tentar reduzir os danos nessa pirâmide.

No Morro do Querosene, bairro da zona oeste de São Paulo, participei da festa do Bumba meu boi, organizada pelo maranhense Tião Carvalho e pelo grupo Cupuaçu. O Bumba meu boi é uma manifestação cultural afro-brasileira. Assisti ao "nascimento do boi", que é comemorado no Sábado de Aleluia. Ao todo são três festas realizadas ao longo do ano: além da já mencionada (nascimento do boi), há o batizado do boi em junho e a morte do boi em data próxima ao dia de finados. Foi muito interessante saber que a festa foi trazida do Maranhão para o Morro e ver que a comunidade maranhense mantém acesa essa tradição há mais de 20 anos, reunindo pessoas de diversas regiões da cidade de São Paulo.

Ainda participei de uma roda de samba do grupo Samba do Querosene, que contou com a participação de Tião Carvalho.

\section{Conclusão: com a palavra, Alice!}

A partir desses encontros de saberes, vivências e experiências, eu discuti a diáspora africana a partir de diferentes perspectivas, e não somente por meio da arqueologia. Isso possibilitou compreender a visibilidade dos mais diversos campos de atuação do movimento negro, da resistência e propagação da cultura africana e afro-brasileira.

Participando das atividades propostas, eu conheci e estabeleci uma troca com diversos pesquisadores, professores e militantes negros que estão produzindo, em diversas áreas, conhecimento, arte e culto aos ancestrais, compondo essa multiplicidade de experiências que formam a diáspora africana. Enquanto pesquisadora negra, foi importante ver outros pesquisadores negros, pois me senti verdadeiramente representada. Esse sentimento gerado também me impulsionou a resistir dentro da universidade diante dos vários processos de opressão que tenho vivenciado. Conhecer pessoas, conversar com elas, saber das suas histórias foi o que mais me encantou e que me despertou mais interesse por essa arqueologia da diáspora africana afrocentrada e colaborativa.

Com a mobilidade sendo organizada a partir de uma orientação colaborativa, o que proporcionou uma articulação representativa e a participação em muitas atividades excelentes, considero que evolui muito nos meus conhecimentos sobre a diáspora africana e supri a demanda a que me propus viajando até São 
“Todo poder ao povo preto”: diálogos sobre práticas colaborativas entre seres em lugares e tempos afrodiaspóricos R. Museu Arq. Etn., 37: 164-177, 2021.

Paulo. Além de tudo, a experiência me trouxe um crescimento pessoal por intermédio da vivência e do (re)conhecimento de mim mesma enquanto uma mulher preta diaspórica.

CARVALHO, P. M.; SOARES, A. M. "All power to the black people": dialogues about collaborative practices between beings in afro-diasporic places and times. R. Museu Arq. Etn. 37: 164-177, 2021.

Abstract: This article reflects upon the experiences lived in a 30-day student mobility program aimed at studying the African diaspora. The project proposal was based on the understanding of the emergence and complexity of the theme and its past and present unfolding. Despite the relevance of these sociocultural issues, few undergraduate (and graduate) courses in Archeology address the contemporary debate on race, racism, and anti-racism - essential for the formation of Afro-descendant students or not. The activities developed in the course of the program were based on an Afro-centered and collaborative theoreticalmethodological approach, aimed at instilling a critical thinking on students about the Afro-diaspora materiality by encouraging self-reflection on their role in a society marked by structural racism. To this end, the program comprised activities beyond those offered in the Museum of Archeology and Ethnology (MAE-USP) and the University of São Paulo (USP), including partnerships with non-archeologists who are scholars of the African diaspora - an experience here termed "collaborative guidance." Throughout the mobility program, Alice searched the USP libraries, visited the MAE-USP technical reserve, attended a thesis defense meeting, and participated in activities promoted by the MAE-USP Educational Department. Outside the University gates, the experience included the organization and attendance to a series of activities related to Afro-diaspora and Afro-centered themes, debates, samba circles, plays, book launches, visits to museums, parades, visits to terreiros, and exhibitions. Beyond the intertwining of our academic trajectories, the mobility also interweaved our Afro-diaspora living experience.

Keywords: African diaspora archeology; Afro-centered thinking; Afro-epistemology, black movement; collaboration.

\section{Referências bibliográficas}

Almeida, S. 2018. O que é racismo estrutural? Letramento, Belo Horizonte.

Amaral, D.M. 2019. Loiceiras, potes e sertões: um estudo etnoarqueológico de comunidades ceramistas no agreste central pernambucano. Tese de doutorado. Universidade de são Paulo, São Paulo.

Bandeira, M.L. 1988. Território negro em espaço branco: estudo antropológico de Vila Bela. Brasiliense, São Paulo.
Carvalho, P.M. 2012. A travessia atlântica de árvores sagradas: estudos de paisagem e arqueologia em área de remanescente de quilombo em Vila Bela/ MT. Dissertação de mestrado. Universidade de São Paulo, São Paulo.

Carvalho, P.M. 2018. Visibilidade do negro: arqueologia do abandono na comunidade quilombola do Boqueirão - Vila Bela/MT. Tese de doutorado. Universidade de São Paulo, São Paulo. 
Colwell-Chanthaphonh, C. 2009. Myth of the anasazi: archaeological language, collaborative communities, and the contested past. Public archaeology 8: 191-207.

Gomes, N.L. 2017. O movimento negro educador: saberes construídos nas lutas por emancipação. Vozes, Petrópolis.

Hooks, b. 2013. Ensinando a transgredir: a educação como prática da liberdade. WMF Martins Fontes, São Paulo.

Moreira, A. 2019. Racismo recreativo. Jandaíra, São Paulo.
Rosa, A. 2013. Pedagoginga, autonomia e mocambagem. Aeroplano, Rio de Janeiro.

Silva, F.A. 2012. O plural e o singular das arqueologias indígenas. Revista de Arqueologia 25: 24-42.

Silva, S.F.S.M.; Mützenberg, D.; Cisneiros, D. 2012. Arqueologia visual: o uso das imagens fotográficas na produção do conhecimento arqueológico e historiografia da arqueologia. Revista do Museu de Arqueologia e Etnologia 22: 137-156.

Walker, S. 2019. Conhecimento desde dentro: os afro-sul-americanos falam de seus povos e suas histórias. Kitabu, Rio de Janeiro. 